\title{
Examen Médico Nacional
}

\section{Chilean National Board of Medicine}

$\mathrm{S}$ Editor: El trabajo de Enríquez y Mena. Habilitación profesional. Condiciones para el aseguramiento de la calidad de la educación médica y condiciones para la confianza recíproca. Experiencia y visión de ASOFAMECH», incluye una Tabla, incorrecta y que a mi juicio puede resultar lesiva para quienes somos allí mencionados.

En efecto, en la página 491 aparece una lista de médicos, todos los cuales ingresamos a la Escuela de Medicina de la Pontificia Universidad Católica de Chile el año 1984, pero no todos titulados en la misma promoción, a quienes se nos describe como egresados de la Universidad de Santiago de Chile, con resultados del Examen Médico Nacional que ninguno de nosotros rindió y, por lo mismo, con porcentajes de respuestas correctas en cada especialidad absolutamente falsos. Como ejemplo, en mi caso particular, pese a haber tenido el puntaje más alto entre todos los egresados de las universidades chilenas al Concurso de Becas y Ciclo de Destinación del año de mi titulación (más de 900 postulantes ese año), y haber egresado con la segunda mejor nota de mi promoción en la Universidad Católica, se me atribuyen resultados mediocres en este examen, y en particular en el área

\section{LA CARTA FUE ENVIADA A LOS AUTORES ALUDIDOS, QUIENES OFRECIERON LA SIGUIENTE RESPUESTA:}

$\mathrm{Sa}$ Editor: Nos dirigimos a usted en relación con carta enviada por el Dr. Julio Urrutia E., en que se refiere a la inclusión de su nombre en una tabla de resultados incluida en el artículo «Habilitación profesional. Condiciones para el aseguramiento de la calidad de la educación médica y condiciones para la confianza recíproca. Experiencia y visión de ASOFAMECH», de nuestra autoría, calificándola de incorrecta y lesiva para los mencionados en esa Tabla».

Es verdad que en dicha Tabla se mencionan nombres reales, escogidos al azar de listas de alumnos egresados hace más de una década. Ésta se quinúrgica, en cuyos internados terminé con nota 7 (siete). El único examen que rendí y aprobé al egresar (así como varios de los mencionados en el artículo en cuestión) fueron las partes Básica, Clínica e Inglés del examen del Educational Council for Foreign Medical Graduates, de los Estados Unidos de Norteamérica.

Solicito que su revista publique una rectificación. Más aún, considerando que entre los citados en la Tabla en cuestión aparecen incluso miembros del Comité Editorial Asesor.

\section{Dr. Julio Urrutia E.}

Jefe de Programa de Postgrado de Ortopedia y Traumatología, Pontificia Universidad Católica de Chile.

\section{REFERENCIAS}

1. Enríuezz O, Mena B. Habilitación profesional. Condiciones para el aseguramiento de la calidad de la educación médica y condiciones para la confianza recíproca. Experiencia y visión de ASOFAMECH. Rev Méd Chile 2005; 133: 483-94.

realizó con el único fin de ejemplificar un formato de resultados en un documento académico confeccionado hace cuatro años, denominado «proyecto Examen Médico Nacional», conocido en las diferentes Escuelas de Medicina y otras instituciones médicas. Los resultados, fechas y universidades mencionados allí son simulados, lo que se señala explícitamente en el documento en referencia y en la publicación de la Revista Médica de Chile, en que se reproduce sin mayores modificaciones la referida Tabla, lo que asumimos como un error involuntario. Jamás esperamos que tuviera un efecto lesivo, como el que tuvo para el Dr. Umutia, a quien hacemos públicas nuestras sinceras disculpas.

Dr. Octavio Enríquez L, Dr. Beltrán Mena C. 